Original Research Paper

\title{
Reliability of Selected Critical Infrastructure Elements
}

\author{
${ }^{1}$ Lucia Figuli, ${ }^{2}$ Matúš Ivančo, ${ }^{2}$ Zuzana Kubíková and ${ }^{1}$ Zuzana Zvaková \\ ${ }^{I}$ Faculty of Security Engineering, Department of Technical Sciences and Informatics, \\ University of Zilina, Zilina, Slovakia \\ ${ }^{2}$ Faculty of Security Engineering, Department of Security Management, \\ University of Zilina, Zilina, Slovakia
}

Article history

Received: 11-01-2018

Revised: 24-02-2018

Accepted: 5-07-2018

Corresponding Author:

Lucia Figuli

Faculty of Security

Engineering, Department of

Technical Sciences and

Informatics, University of

Zilina, Zilina, Slovakia

Email: lucia.figuli@fbi.uniza.com Lucia.Figuli@fbi.uniza.sk

\begin{abstract}
The paper brings an overview of aspect of reliability of selected critical infrastructure elements. Firstly critical infrastructure elements are defined. Extreme loading of such elements and the normative standards are mentioned. The paper brings an overview about a current research connected with critical infrastructure element protection and in conclusions defines new challenges for the research in the problem.
\end{abstract}

Keywords: Critical Infrastructure, Extreme Loads, Reliability, Soft Targets

\section{Introduction}

Over last few years the number of terrorist attacks has increased significantly, causing considerable tension and nervousness. Not only in Europe, but around the world, terrorist attacks and other violent crimes are increasingly concentrated around targets that are easy to access and characterized by a high concentration of people and a relatively low level of protection - soft targets, and targets so-called critical infrastructure. Mainly after the terrorist attacks and the damages of important buildings and life loses a new concept of critical infrastructure protection was adopted in United States of America and in Europe. Critical infrastructure elements threats are mainly connected with the extreme load condition and extreme loading. In the present paper authors would like to bring an overview of aspect of reliability of selected critical infrastructure elements.

\section{Critical Infrastructure Protection}

In the last years critical infrastructure elements were defined. Within the EU member states the European Council Directive 2008/114/EC was given, defined the term of European Critical Infrastructure (ECI). In USA the 42 U.S. Code $\S 5195 \mathrm{c}$ - Critical infrastructures protection was adopted in 2001.

According European directive 'critical infrastructure' means an asset, system or part thereof located in Member States which is essential for the maintenance of vital societal functions, health, safety, security, economic or social well-being of people, and the disruption or destruction of which would have a significant impact in a Member State as a result of the failure to maintain those functions. Analogous US code defines the term "critical infrastructure" as systems and assets, whether physical or virtual, so vital to the United States that the incapacity or destruction of such systems and assets would have a debilitating impact on security, national economic security, national public health or safety, or any combination of those matters.

European directive establishes a procedure for the identification and designation of European critical infrastructures and a common approach to the assessment of the need to improve the protection of such infrastructure in order to contribute to the protection of people. In European system the cross-cutting criteria and the sectoral criteria for the classification of subject into the critical infrastructure elements are defined. Each European member sets own sectors of critical infrastructure, council directive lists European sectors of Critical Infrastructure (ECI) sectors:

\section{i. Energy \\ ii. Transport}

From the above definition and is obvious that the main attention is visibly on the disruption of supplies and services. Infrastructures, in which dangerous substances are handled. Chemical industry factories or nuclear waste sites are not mentioned in the European definition. This is 
interesting to note, as some European countries have a wider definition in place, defines Eismann (2014).

European council directive defines the term of 'critical infrastructures' only, not clearly defines the term of 'critical infrastructure element'. National Council of the Slovak republic on February 8th 2001 adopted law $\mathrm{N}^{\circ} 45 / 2001$ Coll. Where 'Critical infrastructure element' is defined as mainly engineering structure, public service or informational system in the critical information sector. According to sectoral and crosscutting criteria the disruption or the destruction of them could have negative consequences on the function of society and economy and to life quality of inhabitants from the view of their life protection, health, security, property and environment. According to the law 'Civil engineering law' engineering structure is defined as roads, highways, bridges, tunnels, airports etc.

Critical infrastructure elements vary from intangible thinks as services, systems, network to tangible ones as bridge, tunnels water dam etc.

The concept of critical infrastructure was set mainly because of the occurrence of unexpected events. To identify its elements for efficient managing security, it is necessary to define the types of attacks as well as to estimate the probability of occurrence and their expected consequences (Kravcov et al., 2017).

When it is spoken about Critical Infrastructure Protection, it have to be regarded under the influence of the entire spectrum of possible threats, which are classified into three types according to Eismann (2014):

1. Natural events,

2. Technical failure/human error

3. Intentional acts such as terrorism, crime or war

What does it means for the structures and civil engineers? Each possible treat brings unexpected loads condition for structure or building - critical infrastructure elements.

The next Fig. (1) describes logical evolution of loads and action which can effect critical infrastructure element derived from the possible treats.

Table 1: Standards for „extraordinary loads” from different sources

\begin{tabular}{llll}
\hline Type of loads & Impact & Explosion & Earthquake \\
\hline Standards & STN EN 1991-1-7: & STN EN 1991-1-7: & STN EN 1998 \\
& $\begin{array}{l}\text { Eurocode 1. Actions on } \\
\text { structures Part1-7: General } \\
\text { loads. Accidental loads }\end{array}$ & $\begin{array}{l}\text { Eurocode 1. Actions } \\
\text { on structures Part1-7: }\end{array}$ & $\begin{array}{l}\text { Eurocode 8: } \\
\text { Geismic Design } \\
\text { of Buildings }\end{array}$ \\
& & Accidental loads & $\begin{array}{l}\text { STN EN 1991-1-2: } \\
\text { on structures Part1-2: } \\
\text { General loads. Actions } \\
\text { on structures exposed } \\
\text { to fire }\end{array}$ \\
$\begin{array}{l}\text { Extreme weather } \\
\text { Type of loads }\end{array}$ & Snow & & Wind \\
Standards & STN EN 1991-1-3: Eurocode & - & STN EN 1991-1-4: \\
& 1. Actions on structures & & Eurocode 1. Actions on \\
& Part1-3: Snow loads & & Wtructures Part1-4: \\
\end{tabular}

The framework of critical infrastructure was implemented but mainly on the management level. It brings as has been just mentioned common approach to the assessment the protection of such elements in form of 'operator security plants' and methodological guidelines for carrying out risk analyses. But when it is spoken about the security, reliability and resistance of structures (according some terms it can be defined as 'resilience' of structures) discourse are about the interdisciplinary problem which has to include all areas and participants in the process (risk analysis, design, protection, security plant and designer, civil engineers, stakeholders etc.).

External and internal effects on structures are defined as loadings. The set of European standards (generally Eurocode 1) sets out the principles and application rules for determining the load of buildings and structures. In terms of design effects, these threats (described above) can be classified as "extraordinary loads", although the standard (see Table 1) defines only two types of extraordinary loads:

1. Impact loads - impact forces from road vehicles, fork-lift trucks, rail transport, boats and helicopters.

2. Internal explosions - explosions from gas explosions and mixtures of dust and air and local damages from unspecified causes (Bedon et al., 2017).

The loads that can be included as extraordinary loads are listed in the following table also with the standard which deals with the load.

The above-described standards do not concern to:

- The external explosions from explosives caused by terrorist acts, industrial accidents or wars

- Do not address to the issue of residual stability of structures from seismic loads or fire

- Loads of structures from the effects of extreme weather and flood waves from floods 


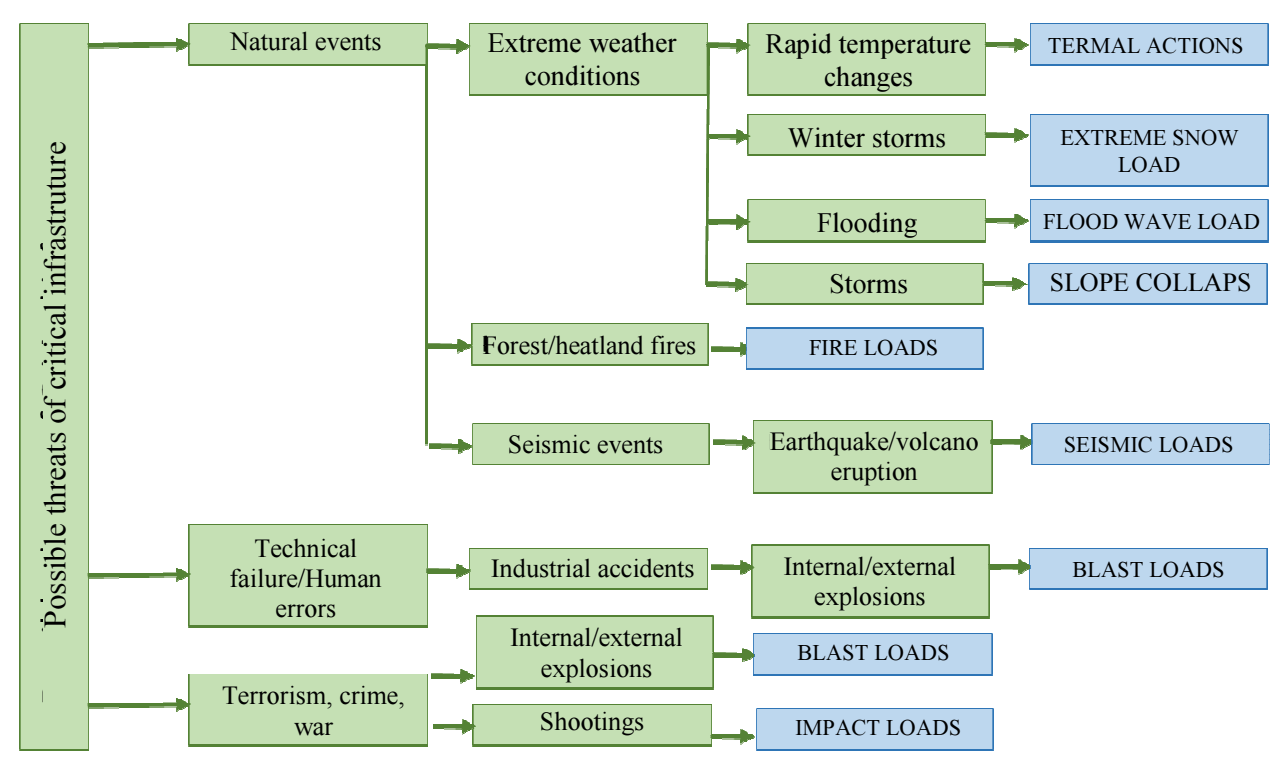

Fig. 1: Possible threats and consequences in the form of structure loading

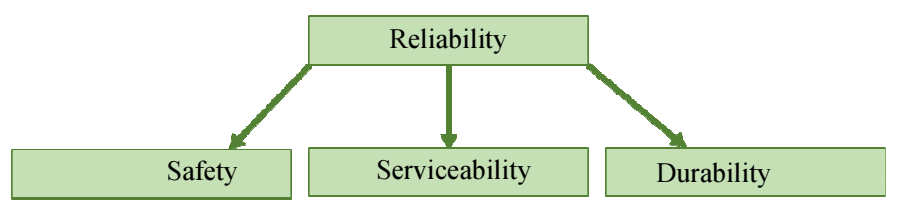

Fig. 2: Partial components of reliability

\section{Reliability of Critical Infrastructure Elements}

Generally, the reliability of an element is understood its ability to perform required functions while maintaining operational variables under the conditions, in limits and in the required time. In the broader point of view according to the Tomica et al. (1992), reliability is the stability of the system in view of all possible malfunctions that may arise in the manufacture, assembly, certain function, transport etc.

Partial components of reliability are (Fig. 2.):

- Safety - not to endanger human health and the environment

- Serviceability - use for the intended purpose

- Durability (lifetime) - Reliable operation time

Standard EN 1990 for the reliability of construction works include next fundamental requirements:

Structural safety: A structure shall be designed and executed in such a way that it will, during its intended life with appropriate degrees of reliability and in an economic way sustain all actions likely to occur during execution and use. Safety of people, the structure and contents.

Serviceability: A structure shall be designed and executed in such a way that it will, during its intended life with appropriate degrees of reliability and in an economic way remain fit for the use for which it is required. Functioning, comfort and appearance of the structure.

As can founded in the handbook by Gulvanessian (2004), depending upon the consequences of failure, the main tools selected in EN1990 Annex B for the management of structural reliability of construction works are:

- Differentiation by $\beta$ (reliability index) values; at this stage, this is a specialist activity

- Modification of partial factors

- Design supervision differentiation

- Inspection during execution (Gulvanessian, 2008)

Reliability index (Fig. 3.) can have different values according to the reference period and design life categories. In the following Table 2 recommended minimum values for reliability index $\beta$ are indicated.

Reliability class that are defined by the reliability index concept, but as is note from Eurocode this concept is only for 50 years. When it is spoken about critical infrastructure elements we have to consider their life 100 years as for bridges (Design working life category 5).

\section{Durability}

As is mentioned by Sanjery et al. (2011), durability is a feature of the element that ensures its long-term 
efficiency under specified operating conditions. According to the EN 1990 standard, the elements are designed so that their expected design lifetime is within the range required by the individual design life categories (Table 3).
The relationship between reliability and durability is the basic characteristic of assessing the technical condition of elements.

In the following Table 4, there are defined individual consequence classes.

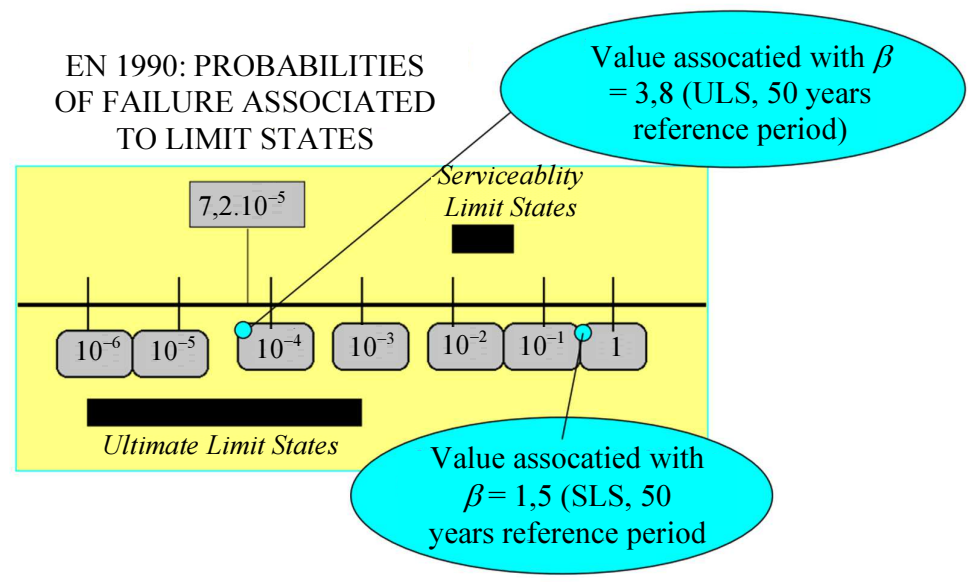

Fig. 3: Partial components of reliability. From Gulvanessian (2008)

Table 2: Recommended minimum values for reliability index $\beta$ (ultimate limit states)

\begin{tabular}{lll} 
& Minimum values for $\beta$ & \\
Reliability class & -1 year reference period & 50 years reference period \\
\hline RC3 & 5,2 & 4,3 \\
RC2 & 4,7 & 3,8 \\
RC1 & 4,2 & 3,3 \\
\hline
\end{tabular}

Table 3: Design life categories

\begin{tabular}{lll}
\hline Design working life category & Design working Indicative life (years) & Examples \\
\hline 1 & 10 & Temporary structures \\
2 & $10-25$ & $\begin{array}{l}\text { Replaceable structural parts, e.g., } \\
\text { gantry girders, bearings } \\
\text { Agricultural and similar structures } \\
\text { Building structures and other common } \\
\text { structures, not listed elsewhere in this table } \\
4\end{array}$ \\
$15-30$ & 50 & $\begin{array}{l}\text { Monumental building structures, highway } \\
\text { and railway bridges and other civil } \\
\text { engineering structures }\end{array}$ \\
\hline
\end{tabular}

Table 4: Definition of consequence classes

\begin{tabular}{lll}
\hline Consequences class & Description & Examples of buildings and civil engineering works \\
\hline $\mathrm{CC} 3$ & $\begin{array}{l}\text { High consequence for loss of human } \\
\text { life, or economic, social or environmental } \\
\text { consequences very great }\end{array}$ & $\begin{array}{l}\text { Grandstands, public buildings where consequences } \\
\text { of failure are high }\end{array}$ \\
Medium consequence for loss of human & $\begin{array}{l}\text { Residential and office buildings, public buildings } \\
\text { life, economic, social or environmental } \\
\text { consequences considerable }\end{array}$ & $\begin{array}{l}\text { Agricultural buildings where people do not normally } \\
\text { Low consequence for loss of human life } \\
\text { and economic, social or environmental } \\
\text { consequences small or negligible }\end{array}$ \\
\hline
\end{tabular}




\section{Current Research}

Research in the area of critical infrastructure is focused mainly on the risk management, as the work of Hudakova (2016), which work is pointed out of the method of risk management of operators of the elements of critical infrastructure or is focused on the process of identifying of critical infrastructure elements as Leitner et al. (2017) made. Another research on critical infrastructure are focused on the measuring societal vulnerability due to failure of critical infrastructure, by Lusková et al. (2018).

In current research is reliability of critical infrastructure comprehended as identifying of critical nodes, describing the cascading failure across mutually dependent systems and describes their relationships. Whole global perspective is described by Murray et al. (2007).

The publication Flood resilience and resistance for critical infrastructure, by McBain et al. (2010) presents how the main topics now confronted by the industry in this area. Principles of flood risk management to place flood resilience and resistance are presented. The case studies describes the teachings identified by infrastructure owners and operators who have been connected with flooding problems in the past. Concept of Great Britain flood risk management for CI (critical infrastructure) is reflected with respect to flood risk assessment, where resilience and resistance measures and investment prioritization are taken into account.

There are some research if resistant elements can be used as a part of critical infrastructure protection as Štoller and Dvořák (2017) who made the tests of ballistic resistance against contact and distant explosions are performed according to the NATO standards.

In the area of research in the extreme load structure are missing the relevant researches focused on the extreme load conditions. As just has been mentioned the research is focused on the evaluation of risk management, relationships among the elements and societal effect of critical infrastructure failure mostly. Generally the research on the one type of extreme loading - the blast loaded has been well developed during the last years, e.g. research by Zhang and Bedon
(2017), but nearly all current explosive blast research (and modelling techniques too) are on deterministic base. Are mainly based on the question if specified explosive weight and stand-off distance, does a particular element of a building persist the blast wave or not? With the note changing in the weather last decades and increasing number of terrorist attack using explosive is fundamental to made research on the effect of extreme loads to protect human lives and property.

\section{Damage and Safety Hazard Risks}

Threat scenarios and possible threat probabilities to assess damage risks, safety hazard risks and life-cycle costs of protective measures has to be taken into account on the risk-based background for the structure. To predict damage and safety hazard risks of critical infrastructure element a probabilistic risk assessment procedure has be taken into account as in the work of Stewart and Melchers (1997). The structural reliability analysis has uses stress limit states and the rating criteria of the valid standards, but the problem is when we could notice above, that standards valid in Europe (Eurocodes) in many cases does not count with such extreme loading which could be part of threat scenarios for critical infrastructure element.

Although a number of decision frameworks exist, these are often developed for initial risk screening or ranking/prioritisation purposes, and so a key issue which is largely unresolved is the quantification of security risks and effectiveness of costs of mitigating measures as mentioned Netherton and Stewart (2009).

Stewart and Melchers (1997) mentioned that a probabilistic risk assessment is preferred way for dealing with uncertainties. Quantitative recommendation can be provided to decision makers in the system of probabilities of damage or safety hazard. When is used an approach based on probability and structural reliability theory it has substantial utility not available from deterministic methods. Society willingly accepts the use of probabilistic approaches in risk-based decision-making and applies them to a spectrum of hypothetically hazardous situations.

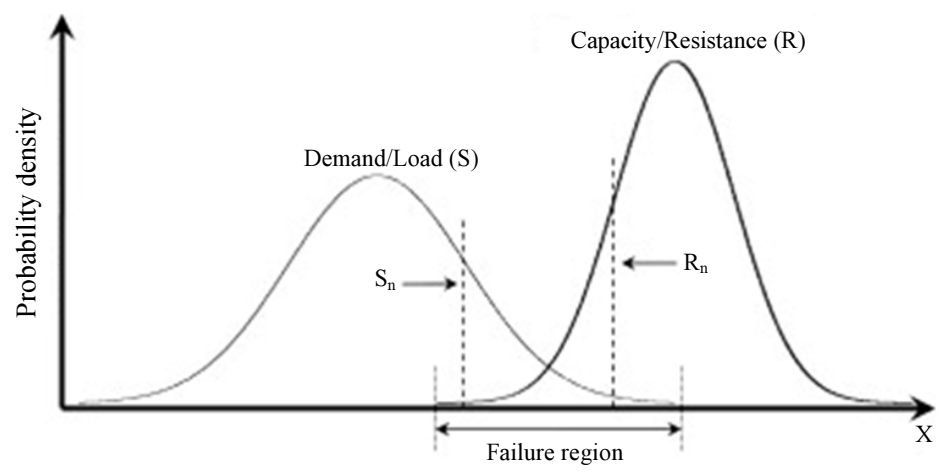

Fig. 4: Relationship between load and resistance. From Netherton and Stewart (2009) 
Predicting damage and safety hazard risks of various critical infrastructure elements requires a need of many input parameters. Minor amount of the parameters are exactly known and so, parameters are assumed to be random variables defined by a probability distribution (Netherton and Stewart, 2009).

\section{Conclusion}

Protection of critical infrastructure elements is legislatively made on the management level of risk management where for risk analysis treat scenarios have to be taken into account (extreme weather conditions (extreme load wind, snow, earthquake), terrorism and industrial explosives (blast load from internal/external explosions).

To predict damage and safety hazard risks of critical infrastructure element a probabilistic risk assessment procedure has be taken into account in the form of structural reliability analysis.

For structural reliability analysis (see Fig. 4) maximal load had to be set arising from the treat scenarios and geometric and mechanical characteristic of the critical infrastructure element have to be know.

Problem is that the load characteristic for such extreme load can be applied from the Eurocodes, because in major part Eurocodes (or valid standard for Europe) do not count with such extreme loading. For example only actions due to internal explosion arising from explosion of dust and gas are considered. Flood wave effect is not considered too.

Risk assessment procedure is interdisciplinary problem where the knowledge of risk analysis, structural behaviour, dynamic of structure have to be involved.

\section{Acknowledgement}

This work was supported by the research projects VEGA $\mathrm{N}^{\circ}$. 1/0240/15 "Process model of critical infrastructure safety and protection in the transport sector" and project VI20152019049 "RESILIENCE 2015: Dynamic Resilience Evaluation of Interrelated Critical Infrastructure Subsystems".

\section{Author's Contributions}

All authors contributed with equal part in this work.

\section{Ethics}

This article is original and as a whole were not published. Authors to the best of their knowledge worked with references and previous work of citated authors. The corresponding author confirms that all of the other authors have read and approved the manuscript and there are no ethical issues involved.

\section{References}

Bedon, C., X. Zhang, F. Santos, D. Honfi and M. Kozłowski et al., 2017. Performance of structural glass facades under extreme loads - design methods, existing research, current issues and trends. Construct. Build. Materials, 163: 921-937. DOI: $10.1016 /$ j.conbuildmat.2017.12.153

Eismann, C., 2014. Trends in critical infrastructure protection in Germany. Transactions VŠB Technical Uni. Ostrava, Safety Eng. Series, 9: 1-6. DOI: $10.2478 /$ tvsbses-2014-0008

Gulvanessian, H., 2004. Designers' Handbook to Eurocode 1: Basis of Design. 1st Edn., p: 123.

Gulvanessian, H., 2008. EN 1990: Eurocode: Basis of Structural Design: The Key Head Eurocode An Innovative Structural Safety Code Of Practice. EUROCODES, Moscow.

Hudakova, M., 2016. Risk management to protect critical infrastructure. Sci. Populat. Protect., 2: 1-1.

Kravcov, A., E.B. Cherepetskaya and V. Pospichal, 2017. Durability of Critical Infrastructure, Monitoring and Testing: Proceedings of the ICDCF 2016. 1st Edn., Springer Nature, ISBN-10: 9811032467, pp: 261.

Leitner, B., L. Môcová and M. Hromada, 2017. A new approach to identification of critical elements in railway infrastructure. Procedia Eng., 187: 143-149. DOI: 10.1016/j.proeng.2017.04.360

Lusková, M., M. Titko and B. Leitner, 2018. Multilevel approach to measuring societal vulnerability due to failure of critical land transport infrastructure. Proceedings of the 20th World Multi-Conference on Systemics, Cybernetics and Informatic, (SCI'18), pp: 224-228.

McBain, W., D. Wilkes and M. Retter, 2010. Flood Resilience and Resistance for Critical Infrastructure. 1st Edn., CIRIA, British Library, ISBN-10: 978-086017-688-6, pp: 130.

Murray, A.T. and T. Grubesic, 2007. Critical Infrastructure: Reliability and Vulnerability. 1st Edn., Springer Science and Business Media, Berlin; New York, ISBN-10: 354068056X, pp: 311.

Netherton, M.D. and M.G. Stewart, 2009. The effects of explosive blast load variability on safety hazard and damage risks for monolithic window glazing. Int. J. Impact Eng., 36: 1346-1354. DOI: 10.1016/j.ijimpeng.2009.02.009

Sanjery, K.A. A. A., N.A. Rahman and K.S. Baharudin, 2011. Aspects of reliability and quality management of buildings in accordance with eurocode. Procedia Eng., 20: 166-173. DOI: 10.1016/j.proeng.2011.11.152

Stewart, M.G. and R.E. Melchers, 1997. Probabilistic Risk Assessment of Engineering Systems. 1st Edn., Springer Netherlands, Chapman and Hall, London, New York, ISBN-10: 0412805707, pp: 274. 
STN EN 1991-1-2: Eurocode 1. Actions on structures Part1-2: General loads. Actions on structures exposed to fire.

STN EN 1991-1-3: Eurocode 1. Actions on structures Part1-3: Snow loads.

STN EN 1991-1-4: Eurocode 1. Actions on structures Part1-4: Wind actions.

STN EN 1991-1-7: Eurocode 1. Actions on structures Part1-7: General loads. Accidental loads.

STN EN 1991-1-7: Eurocode 1. Actions on structures Part1-7: General loads. Accidental loads.

STN EN, 1998 Eurocode 8: Seismic Design of Buildings
Štoller, J. and P. Dvořák, 2017. Field tests of cementitious composites suitable for protective structures and critical infrastructure. Key Eng. Materials, 722: 3-11.

DOI: 10.4028/www.scientific.net/KEM.722.3

Tomica, V., A. Sokolík and Š. Zemko,1992. Údržba a Rekonštrukcia Mostov. 1st Edn., Alfa Bratislava.

Zhang, X. and C. Bedon, 2017. Vulnerability and protection of glass windows and facades under blast: Experiments, methods and current trends. Int. J. Structural Glass Adv. Materials Res., 1: 10-23. DOI: $10.3844 /$ sgamrsp.2017.10.23 